\title{
DOES THE A9285G POLYMORPHISM IN COLLAGEN TYPE XII $\alpha 1$ GENE ASSOCIATE WITH THE RISK OF ANTERIOR CRUCIATE LIGAMENT RUPTURES?
}

Ficek K ${ }^{1}$, Stepien-Slodkowska M², Kaczmarczyk M³ ${ }^{3}$, Maciejewska-Karlowska A ${ }^{4}$, Sawczuk M ${ }^{4}$, Cholewinski J ${ }^{1,5}$, Leonska-Duniec $\mathrm{A}^{2}$, Zarebska A ${ }^{6}$, Cieszczyk $\mathrm{P}^{2}$, Zmijewski $\mathrm{P}^{7, *}$

*Corresponding Author: Piotr Zmijewski, Ph.D., Institute of Sport, Department of Physiology, Trylogii 2/16, 01-982 Warsaw, Poland. Tel.: +48-228340812. Fax:+480228350977. E-mail: piotr.zmijewski@insp.waw.pl

\begin{abstract}
One of the most severe injuries sustained by athletes is rupture of the anterior cruciate ligament (ACL). Recent investigations suggest that a predisposition for ACL rupture may be the result of specific genetic sequence variants. In light of this, we decided to investigate whether the COL12A1 A9285G polymorphism was associated with ACL ruptures in Polish football players.

We compared genotypic and allelic frequencies of the COL12A1 A9285G polymorphism in two groups of athletes: 91 male football players $(23 \pm 3$ years) with surgically diagnosed primary ACL ruptures who qualified for ligament reconstruction (cases) and 143 apparently healthy, male football players of the same ethnicity, a similar age category, and a comparable level of exposure to ACL injury, who were without any self-reported history of ligament or tendon injury (controls). DNA samples extracted from the oral epithelial cells were genotyped by us-
\end{abstract}

\footnotetext{
${ }^{1}$ Galen Orthopaedics, Bierun, Poland

${ }^{2}$ Department of Physical Culture and Health Promotion, University of Szczecin, Poland

${ }^{3}$ Department of Clinical and Molecular Biochemistry, Pomeranian Medical University, Szczecin, Poland

${ }^{4}$ Department of Genetics, University of Szczecin, Szczecin, Poland

${ }^{5}$ Boni Fratres Catoviensis, Katowice, Poland

${ }^{6}$ Department of Sport Education, Academy of Physical Education and Sport, Gdańsk, Poland

${ }^{7}$ Department of Physiology, Institute of Sport, Warsaw, Poland
}

ing a real-time polymerase chain reaction (Ri-TiPCR) method.

The genotype distribution in the cases were not different from those in controls $(p=0.70)$. The frequency of the $\mathrm{G}$ allele was lower in the cases $(18.1 \%)$ but not statistically significant $(p=0.40)$ when compared with controls $(21.3 \%)$.

Our results are in contradiction to the hypothesis that the COL12A1 A9285G polymorphism is associated with a predisposition for ACL injury. However, these conclusions should be supported with more experimental studies on $C O L 12 \mathrm{Al}$ polymorphisms.

Keywords: Anterior cruciate ligament (ACL) rupture; Collagen; COL12A1 gene; Polymorphism.

\section{INTRODUCTION}

One of the most severe injuries sustained by athletes is rupture of the anterior cruciate ligament (ACL) [1]. The exact etiology of ACL ruptures is poorly understood, but recently conducted investigations indicate that around $70.0 \%$ of ACL ruptures are the consequence of forces applied to the knee at the time of injury, which result from the athlete's own movements and do not involve contact with another athlete or object [2]. That seems to be the reason that the risk of ACL rupture is significantly higher in sports requiring change in direction and rapid deceleration during cutting, pivoting and landing [3]. Therefore, it is not surprising that one of the groups of athletes with the highest frequency of ACL rupture are football players [4]. 
Analyzing individual cases of ACL injuries in football players raises the question as to why one member of a team (with the same load and movement character) is exposed to ACL injury, while fellow team mates are not. Recent investigations suggest that the risk of ACL rupture results from familial predispositions and specific genetic sequence variants [5]. At this point in time, only a few studies have given evidence of the connection between ACL injury and specific genetic risk factors [6-10], mostly among sequence variants within the $\mathrm{CO}$ L5A1 and COL1A1 genes.

Anterior cruciate ligaments are collagenous structures consisting of water and fibro-cartilaginous specific proteins, which build collagen fibrils [11]. The main structural components of this ligament are collagens type I, III-VI, XII and XIV, but also proteoglycans such as decorin, lumican and versican, and glycoproteins such as elastin, tenascin $\mathrm{C}$ and cartilage oligomeric matrix protein (COMP) [12].

In the present state of knowledge, any proteins (and what is more, any genes that encode these proteins) that are functionally associated with ligaments could be potential candidates [13-15]. Hence, any such genes and proteins that have already been implicated with ACL injury should be designated as candidates of priority [7]. In our study, we decided to investigate $C O L 12 \mathrm{Al}$, which is one of the less frequently studied genes in the context of predisposition to ACL injury.

The COL12A1 gene (121 kb; mapped to chromosome 6q12-q13) encodes the $\alpha 1$ chains of the various long (XIIA) and short (XIIB) homotrimeric isoforms of type XII collagen [16,17]. According to the database hosted by the National Center for Biotechnology and Information (NCBI), five single nucleotide polymorphisms (SNPs) are shown in COL12A1 exons. Only two of them (rs240736 and rs970547) were identified as non synonymous SNPs (i.e. SNPs that change the amino acid sequence in the gene product) [13].

In one of the previous studies, it was suggested that especially the $\mathrm{A} / \mathrm{G}$ transition at position 162 of exon 65 (9285 A/G, S3058G, rs970547) may alter the biomechanical properties of the collagen fibril and thus may increase the risk of ACL ruptures [18]. In light of the facts mentioned above, we decided to investigate whether the COL12A1 A9285G polymorphism was associated with ACL ruptures in Polish football players.

\section{MATERIALS AND METHODS}

Study Subjects. A total of 91 male football players ( $23 \pm 3$ years) with surgically diagnosed primary ACL ruptures who qualified for ligament reconstruction, were recruited for this study through Galen Orthopaedics, Bierun, Poland. The control group comprised 143 apparently healthy, male football players ( $25 \pm 2.6$ years), of the same ethnicity, a similar age category, and a comparable level of exposure to ACL injury, who were without any selfreported history of ligament or tendon injury.

Ethics Committee. The study was conducted in accordance with the ethical standards as described by Kruk [19]. Additionally, the Pomeranian Medical University (Szczecin, Poland) Ethics Committee approved the details of this study and all related informational and consent documentation before any data collection. In accordance with the Pomeranian Medical University Ethics Committee's guidelines, the investigator informed all the subjects as to the benefits and possible risks associated with participation in the study, and all subjects signed a written informed consent document indicating their voluntary participation.

Genotyping. Genomic DNA was extracted from the oral epithelial cells using GenElute Mammalian Genomic DNA Miniprep Kit (Sigma-Aldrich Chemie, Steinheim, Germany) according to manufacturer's protocol. Allelic discrimination of the A9285G COL12A1 (rs970547) polymorphic site was performed using a TaqMan Pre-Designed SNP Genotyping Assays (Applied Biosystems, Foster City, CA, USA), including primers and fluorescently labelled (FAM and VIC) MGB probes for the detection of the alleles. All samples were genotyped on a Rotor-Gene real-time polymerase chain reaction (Re-Ti-PCR) instrument (Corbett Research, Sydney, NSW, Australia). Thermal cycler conditions were as follows: an initial step at $95{ }^{\circ} \mathrm{C}$ for $5 \mathrm{~min}$., followed by 45 cycles of denaturation at $94{ }^{\circ} \mathrm{C}$ for 15 seconds and annealing/extension at $60{ }^{\circ} \mathrm{C}$ for $1 \mathrm{~min}$.

Statistical Analysis. Any differences in genotype and allele frequency were analyzed using $\chi^{2}$ tests (or Fisher exact tests). Odds ratios (OR) with $95 \%$ confidence intervals $(95 \% \mathrm{CI})$ were calculated. All calculations were performed using Statistica (StatSoft Inc., Tulsa, OK, USA; 2011). STATISTICA (data analysis software system, version 10, 
www.statsoft.com) was used for computing statistics, except Hardy-Weinberg equilibrium which was tested with the programming language and environment R (http://www.r-project.org) and the test for linear trend, which was performed using the STATCALC module in Epi Info (http://wwwn.cdc.gov/ epiinfo). The $p<0.05$ values were considered to be statistically significant.

\section{RESULTS}

Genotype distributions met Hardy-Weinberg proportions in the control group $(p=0.81)$ and in the cases $(p=1.0)$. The distributions of the A9285G COL12A1 genotypes and alleles are given in Table 1. The genotype distribution in the cases were not different from those in controls $(p=0.70)$. Underrepresentation of the GG genotype in the ACL rupture group was not statistically significant $(p=$ 0.744, Fisher's exact test, recessive mode: GG vs. $\mathrm{GA}+\mathrm{AA})$. The frequency of the $\mathrm{G}$ allele was lower in the cases $(18.1 \%)$, but not statistically significant $(p=0.40)$ when compared with controls $(21.3 \%)$. Given the G allele, the likelihood of ACL injury was 0.82 times higher (95\% CI: $0.50-1.34 ; p<0.00001$; $\left.p_{\text {ad }}<0.0001\right)$ than in the control group.

\section{DISCUSSION}

The role of genetics in sport research increases with every passing year [20,21]. Knowledge of the role of individual genes in the processes occurring in the human body can also be used in sport rehabilitation and injury prevention [22]. Precise determination of genotypes at risk for acute or chronic diseases related to sport will probably enable adjustments in individual training plans to greatly minimize the risk of injury.

Approximately two-thirds of ACL tissue consists of water. The rest is made up of tightly packed parallel collagen fibril bundles consisting predominately of type I collagen fibrils $(60.0-80.0 \%$ dry mass of ligament) [11].

Collagen XII belongs to the subfamily of fibrilassociated collagens with interrupted triple helices (FACIT) $[23,24]$ that are believed to form interfibrillar connections and mediate fibril interaction with other extracellular and cell surface molecules within tendons and other tissues [24,25]. On the basis of this fact, we suspect that collagen XII may be considered an influential component in ligament and tendon strength and flexibility.

This assumption seems to be indirectly confirmed by the fact that the key elements of tendons' stretch-responsiveness have been identified in regulatory regions of the COL12A1 gene. Additionally, earlier studies indicated that collagen XII significantly promotes the contraction of collagen gels (such as tenascin C) and consequently modulates the cellular response of tissue to mechanical stress [26-28]. Furthermore, September et al. [8] suggested collagen XII may be involved in similar biological processes as both tenascin $\mathrm{C}$ and type $\mathrm{V}$ collagen, i.e., regulation of the assembly of fibrils (fibrillogenesis).

Table 1. Genotype and allele frequencies of the A9285G COL12A1 gene.

\begin{tabular}{|l|c|c|c|c|c|c|}
\hline Subjects & HWE & $\begin{array}{c}\text { Genotype } \\
\boldsymbol{n}(\mathbf{\%})\end{array}$ & $\boldsymbol{p}$ Values & $\begin{array}{c}\text { Allele } \\
\mathbf{( \% )}\end{array}$ & $\begin{array}{c}\text { OR } \\
\mathbf{( 9 5 \%} \text { CI) }\end{array}$ & $\begin{array}{c}\text { Allele } \boldsymbol{p} \\
\text { Value }\end{array}$ \\
\hline $\begin{array}{l}\text { Cases } \\
(n=91)\end{array}$ & 1.0 & $\begin{array}{c}\text { AA: } 61(67.0) \\
\text { AG: } 27(29.7) \\
\text { GG: } 3(3.3)\end{array}$ & $\begin{array}{c}0.701^{\mathrm{a}} \\
p_{\mathrm{D}} 0.487^{\mathrm{b}} \\
p_{\mathrm{R}} 0.744^{\mathrm{b}}\end{array}$ & $\begin{array}{c}\mathrm{A}(81.9) \\
\mathrm{G}(18.1)\end{array}$ & $\begin{array}{c}0.82 \\
(0.50-1.34)\end{array}$ & $0.400^{\mathrm{a}}$ \\
\hline $\begin{array}{l}\text { Controls } \\
(n=143)\end{array}$ & 0.808 & $\mathrm{AA:} 89(62.2)$ & & $\mathrm{AG}(78.7)$ & & \\
\hline
\end{tabular}

HWE: Hardy-Weinberg equilibrium.

${ }^{\mathrm{a}} \chi^{2}: p$ value.

${ }^{\mathrm{b}} p_{\mathrm{D}}$ and $p_{\mathrm{R}}$ are two-sided Fisher's exact test probabilities with dominant (GG+AG $v s$. AA) and recessive (GG vs. AG+AA) modes of inheritance of minor alleles $(\mathrm{G})$, respectively. 
The A9285G COL12A1 polymorphism within exon 65 , is a non synonymous coding variant, which changes the amino acid at position 3058 from a serine to a glycine. Although the wild type serine amino acid is a neutral polar amino acid with a larger side chain than the substituted non polar neutral glycine amino acid, some investigators speculate that this change in amino acid sequence may alter the biomechanical properties of the collagen fibril [29]. On the other hand, it is not proven that this SNP has any effect on protein expression or function.

The first report concerning the possible importance of COL12Alvariants for achilles tendon injuries did not identify a statistically significant difference in the genotype or allele distribution in the A9285G COL12A1 polymorphism [29]. On the other hand, the same investigators showed that the A9285G COL12A1 polymorphism is associated with ACL ruptures in females [29]. The obtained results suggested that females with an AA genotype are at increased risk for ACL ruptures (AA vs. GT+GG; $\mathrm{OR}=2.4 ; 95 \%$ CI $1.0-5.5 ; p<0.05)$. Additionally, September et al. [13] observed a trend for the AA genotype to be overrepresented (AA vs. GA+GG; $p=0.08)$ in female participants with a family history of ligament injury. The ambiguity of the results obtained by September et al. [13] and Posthumus et al. [29] and a lack of other studies concerning the role A9285G COL12A1 in ACL injures may be considered as one of the most important reasons to conduct repeated investigations in order to identify the genetic background of individuals predisposed to tendon and ligament injury.

Our results were contrary to the hypothesis that the $\mathrm{A} 9285 \mathrm{G} \mathrm{COL12A1}$ polymorphism is associated with ACL injuries. We did not find any statistical difference in the A9285G genotype and allele frequencies in male football players with surgically confirmed primary ACL ruptures compared to injury-free athletes. To summarize, considering we only investigated male subjects, we reached a similar conclusion as September et al. [13].

In our investigation, the ACL injury group closely resembled the control group of injury-free athletes in numerous aspects, being of similar ages and ethnicities and identical athletic disciplines. The last of these is a key component due to the variability of inciting events among different disciplines. Participants from the control group in our study had the similar internal and external risk factors relating to the examined phenotype, overcoming a known limitation of case-control studies.

We investigated male football players with surgically confirmed primary ACL rupture, who were qualified for an ACL reconstruction procedure. The control group comprised of only males of the same ethnicity, similar in age, participating in the same sport, their knee joints being exposed to comparable forces and movements, controlling the many internal and external risk factors. Thanks to this solution in our investigations cases and controls are similar in variables that may be related to the phenotype that is under examination, as well as the inciting events is very difficult, a known limitation of casecontrol studies.

The homogeneity of the investigated groups seems to be a strength of this study, however, this fact may be considered as a limitation, because we did not manage to confirm or deny the important role of the investigated polymorphism with regard to the risk of ACL injury in women. We included only male participants, but it should be noted that women are 2-3 times more likely to sustain an ACL injury than men [18]. A number of intrinsic risk factors classified as anatomical, hormonal, or neuromuscular, have been linked to this observed phenomenon. In the case of female patients, each of the aforementioned factors may be more likely to affect the gene environmental interaction, causing significantly higher incidence of this polymorphism's association with ACL injuries [30,31], a relationship that is not seen as clearly in men.

In conclusion, this study found that there is no association between the A9285G COL12A1 polymorphism and ACL ruptures in men. On the other hand, the lack of statistical significance in genotype and allele distribution of $\mathrm{A} 9285 \mathrm{G} \mathrm{COL12A1} \mathrm{shown}$ in our investigation, does not necessarily mean that the investigated polymorphism has no effect on ACL injuries. Tendon and ligament injuries are complex, multifactorial conditions, caused by interactions of a number of different proteins, encoded by different genes on different chromosomes (gene-gene interactions), and the interactions of these genetic components with different environmental factors (geneenvironment interactions) [13]. Thus, our findings should be supported with more experimental studies on COL12A1 polymorphisms including their inter- 
action with other genes. Additionally, our results need to be confirmed in a larger sample of subjects. Lastly, it should be noted that genetic association studies must always be interpreted with caution.

Declaration of Interest. The authors report no conflicts of interest. The authors alone are responsible for the content and writing of this article.

\section{REFERENCES}

1. Brooks JHM, Fuller CW, Kemp SPT, Reddin DB. Epidemiology of injuries in English professional rugby union: Part 1 match injuries. $\mathrm{Br}$ J Sports Med. 2005; 39(10): 757-566.

2. Marshall SW, Padua D, McGrath M. Incidence of ACL injuries. In: Hewett TE, Schultz SJ, Griffin LY, Eds. Understanding and Preventing Noncontact ACL injuries. Champaign, IL: Human Kinetics. 2007:5-30.

3. Parkkari J, Pasanen K, Mattila VM, Kannus $\mathrm{P}$, Rimpela A. The risk for a cruciate ligament injury of the knee in adolescents and young adults: A population-based cohort study of 46500 people with a 9 year follow-up. $\mathrm{Br} \mathrm{J}$ Sports Med. 2008; 42(6): 422-426.

4. Majewski M, Habelt S, Steinbrück K. Epidemiology of athletic knee injuries: A 10-year study. Knee. 2007; 13(3): 184-188

5. Flynn RK, Pedersen CL, Birmingham TB, Kirkley A, Jackowski D, Fowler PJ. The familial predisposition toward tearing the anterior cruciate ligament: A case control study. Am J Sports Med. 2005; 33(1): 23-28.

6. Mokone GG, Schwellnus MP, Noakes TD, Collins M. The COL5A1 gene and Achilles tendon pathology. Scand J Med Sci Sports. 2006; 16(1): 19-26.

7. September AV, Mokone GG, Schwellnus MP, Collins M. Genetic risk factors for Achilles tendon injuries. Int Sport Med J. 2006; 7(6): 201215.

8. September AV, Schwellnus MP, Collins M. Tendon and ligament injuries: the genetic component. Br J Sports Med. 2007; 41(4): 241-466.

9. September AV, Cook J, Handley CJ, van der Merwe L, Schwellnus MP, Collins M. Variants within the COL5A1 gene are associated with Achilles tendinopathy in two populations. $\mathrm{Br} \mathrm{J}$ Sports Med. 2009; 43(5): 357-365.

10. Stępień-Słodkowska M, Ficek K, Eider J, Leońska-Duniec A, Maciejewska-Karłowska A, Sawczuk M, et al. The $+1245 \mathrm{G} / \mathrm{T}$ polymorphisms in the collagen type I alpha 1 (COL1A1) gene in Polish skiers with anterior cruciate ligament injury. Biol Sport. 2013; 30(1): 57-60.

11. Hoffmann A, Gross G. Tendon and ligament engineering in the adult organism: mesenchymal stem cells and gene-therapeutic approaches. Int Orthop. 2007; 31(6): 791-797.

12. Frank CB. Ligament structure, physiology and function. J Musculoskelet Neuronal Interact. 2004; 4(2): 199-201.

13. September AV, Posthumus M, van der ML, Schwellnus M, Noakes TD, Collins M. The COL12A1 and COL14A1 genes and Achilles tendon injuries. Int J Sports Med. 2008; 29(3): 257-263.

14. Bell RD, Sandra BS, Shultz S, Wideman L, Henrich VC. Collagen gene variants previously associated with anterior cruciate ligament injury risk are also associated with joint laxity. Sports Health. 2012; 4(4): 312-318.

15. O'Connell K, Saunders CJ, Collins M. Collagen gene sequence variants in exercise-related traits. Centr Eur J Sport Sci Med. 2013; 1(1): 3-17.

16. Gerecke DR, Olson PF, Koch M, Knoll JH, Taylor R, Hudson DL, et al. Understanding and preventing noncontact anterior cruciate ligament injuries: A review of the Hunt Valley II meeting, January 2005. Am J Sports Med. 2006; 34(9): 1512-32.

17. Kania AM, Reichenberger E, Baur ST, Karimbux NY, Taylor RW, Olsen BR, et al. Structural variation of type XII collagen at its carboxylterminal $\mathrm{NC} 1$ domain generated by tissue-specific alternative splicing. J Biol Chem. 1999; 274(31): 22053-22059.

18. Posthumus M, September AV, O'Cuinneagain D, van der Merwe W, Schwellnus MP, Collins M. The COL5A1 gene is associated with increased risk of anterior cruciate ligament ruptures in females. Am J Sports Med. 2009; 37(11): 2234-2240. 
19. Kruk J. Good scientific practice and ethical principles in scientific research and higher education. Centr Eur J Sport Sci Med. 2013; 1(1): 25-29.

20. Leońska-Duniec A. Genetic research in modern sport. Centr Eur J Sport Sci Med. 2013; 3(3): 19-26.

21. Pokrywka A, Kaliszewski P, Majorczyk E, Zembroń-Łacny A. Genes in sport and doping. Biol Sport. 2013; 30(3): 155-161.

22. Sawczuk M, Maciejewska A, Cięszczyk P, Eider J. The role of genetic research in sport. Sci Sports. 2001; 26(5): 251-258.

23. Mayne R, Brewton RG. New members of the collagen superfamily. Curr Opin Cell Biol. 1993; 5(5): 883-890.

24. Shaw LM, Olsen BR. FACIT collagens: Diverse molecular bridges in extracellular matrices. Trends Biochem Sci. 1991; 16(5): 191-194.

25. Young BB, Zhang G, Koch M, Birk DE. The roles of types XII and XIV collagen in fibrillogenesis andmatrix assembly in the developing cornea. J Cell Biochem. 2007; 87(2): 208-220.

26. Akutsu N, Milbury CM, Burgeson RE, Nishiyama T. Effect of type XII or XIV collagen NC-3 domain on the human dermal fibroblast migration into reconstituted collagen gel. Exp Dermatol. 1999; 8(1): 17-21.

27. Chiquet M. Regulation of extracellular matrix gene expression by mechanical stress. Matrix Biol. 1999; 18(5): 417-426.

28. Nishiyama T, McDonough AM, Bruns RR, Burgeson RE. Type XII and XIV collagens mediate interactions between banded collagen fibers in vitro and may modulate extracellular matrix deformability. J Biol Chem. 1994; 269(45): 28193-28199.

29. Posthumus M, September AV, O'Cuinneagain D, van der Merwe W, Schwellnus MP, Collins M. The association between the COL12A1 gene and anterior cruciate ligament ruptures. Br J Sports Med. 2010; 44(16): 1160-1165.

30. Renstrom P, Ljungqvist A, Arendt E, Beynnon B, Fukubayashi T, Garrett W, et al. Non-contact ACL injuries in female athletes: An International Olympic Committee current concepts statement. Br J Sports Med. 2008; 42(6): 394-412.

31. Ireland ML. Anterior cruciate ligament injury in female athletes: Epidemiology. J Athl Train. 1999; 34(2): 150-154. 